\title{
IMPACT OF BODY MASS INDEX (BMI) ON FLUID AND ELECTROLYTE BALANCE IN HEALTHY INDIVIDUALS
}

\author{
SHARMA R.C. ${ }^{*}$, BHATTACHARYA N. ${ }^{1}$, SHARMA S. ${ }^{2}$ AND GARG K. ${ }^{2}$ \\ ${ }^{1}$ AIMST University, Semeling, 08100Bedong, Kedah, Malaysia. \\ ${ }^{2}$ Resident Medical Officer, RVMS Hospital, Nalasopara, Mumbai- 401203, MS, India. \\ *Corresponding Author: Email- drsharmax@gmail.com
}

Received: February 27, 2013; Accepted: March 04, 2013

\begin{abstract}
Body fluid volume and electrolyte concentration are normally maintained within very narrow limits despite wide variations in dietary intake, metabolic activity \& environmental stresses. It is hypothesized that water retention in healthy people demonstrates weight fluctuations within 2-3 $\mathrm{kg}$ while obese subjects demonstrate more than 4 to $5 \mathrm{~kg}$. Unpublished data reveals that people with increased weight gain, resorting to restricted diet, prolonged exercise or decreased calorie intake, experienced fluctuations in body weight and altered fluid electrolyte balance. Sodium intake, particularly from processed foods is reported to be one of the causes of water related weight gain. However, studies on fluid balance of healthy subjects with increased body mass index are very scanty. The present study has observed linear relation between BMI and water retention. We hypothesize that subject with higher BMI demonstrated water retention leading to increase fat store and weight gain.
\end{abstract}

Keywords- Body Mass Index (BMI), Fluid and electrolyte balance, Healthy individuals

Citation: Sharma R.C., et al. (2013) Impact of Body Mass Index (BMI) on Fluid and Electrolyte Balance in Healthy Individuals. International Journal of Medical and Clinical Research, ISSN: 0976-5530 \& E-ISSN: 0976-5549, Volume 4, Issue 1, pp.-245-247.

Copyright: Copyright@2013 Sharma R.C., et al. This is an open-access article distributed under the terms of the Creative Commons Attribution License, which permits unrestricted use, distribution and reproduction in any medium, provided the original author and source are credited.

\section{Introduction}

Recent studies demonstrated that body mass index (BMI) above 25 $\mathrm{kg} / \mathrm{m}^{2}$ in young adults is associated with an increased risk for endstage renal disease in normal as well as subjects with a specific renal parenchymal disorder, hypertension, or diabetes [1]. An independent correlation between $24 \mathrm{Hrs}$. urinary calcium excretion and other factors such as demographic, dietary, and urinary factors have been reported [2]. Chung, et al (2012) investigated the influence of over weight on $24 \mathrm{Hrs}$. urine chemistry studies and recurrent urolithiasis (UL) in children and did not find difference in $24 \mathrm{Hrs}$. urine chemistry [3]. In another study, a positive relationship was observed between BMI and excretion of inorganic constituents of urine [4]. Siener, et al [5] found an inverse relationship between urinary $\mathrm{pH}$ and $\mathrm{BMI}$. However the existing data failed to demonstrate mechanisms underlying of relationship between BMI and renal handling of water and urine output in normal subjects. Further it is still not clear whether it is the water related increase in fat store, which is responsible for weight gain leading to increase in BMI or it is the feedback loop between adipose tissue and central neural mechanism modulating fluid electrolyte balance and thus results in fluid retention. We therefore aimed to establish whether healthy subjects with increased BMI are associated with altered fluid electrolyte balance and demonstrate retention of fluid as compared with normal BMI and attempt to identify the factors responsible for altered fluid electrolyte balance in healthy subjects with increased BMI. Present study is aimed to study the relationship of BMI with physical characteristics of urine such as volume, specific gravity and $\mathrm{pH}$ as index of fluid balance in healthy subjects with increased BMI.

\section{Material and Methods}

The 30 normotensive male healthy subjects for the study were selected amongst the patient's relatives visiting RVMS Hospital Mumbai, India on voluntary basis. Salt intake index and sweat index of the each subject was assessed as rating scale based on dietary habit and life style. The height and weight of the subjects were measured to calculate BMl of the subjects. The subjects were screened for basal blood pressure in supine condition after 10 minutes of rest followed by detailed medical history to ensure that subjects included in the study are without any chronic disease. All the subjects were found normotensive and normal healthy individuals. A written informed consent by the subjects was obtained for participation in the study. The protocol for the study was duly approved by the institutional ethical committee of AIMST University. The subjects for present study were of age ranging between 25 to 35 years and BMI ranging between 20 to $38 \mathrm{~kg} / \mathrm{m}$.

\section{Methodology}

The subjects were informed about study and relevant preparations such as constituents of breakfast, time of breakfast and liquid intake prior to inclusion of the study to ensure uniform homeostatic environment. After $2 \mathrm{Hrs}$. of fasting, subjects were asked to void urine. Each subject was asked to drink $500 \mathrm{ml}$ of water quickly and wait in the lab and asked to void urine at an interval of 30 minutes, 60 minutes and 90 minutes. Urine samples were collected for volume, 
specific gravity, pH measurement. Renal output/ per hour was computed using sum of total urine volume collected divided by 1.5. Results were tabulated for further analysis and interpretation. The statistical analysis was done with the help of computer software Statistical Package for Social Sciences (SPSS) version 11.5. All values were presented as mean \pm standard deviation. Correlation between BMI values and urinary outflow per hour, specific gravity and $\mathrm{pH}$ was assessed using correlation coefficient.

\section{Observation}

We determine urine output, specific gravity and $\mathrm{pH}$ of urine of 30 normotensive male healthy subjects (age 24-45 Yrs.) with BMI from 20 to $38 \mathrm{~kg} / \mathrm{m}$ after ingestion of $500 \mathrm{ml}$ water. The subjects were categorized according to BMl as group I (BMI $\left.=25-29.9 \mathrm{~kg} / \mathrm{m}^{2}\right)$ and group II $\left(B M I=30-36 \mathrm{~kg} / \mathrm{m}^{2}\right)$. The mean age of the subjects was $36.03 \pm 14.48$ while $32.09 \pm 9.9$ in group I and $38.32 \pm 12.46$ in group II.

Mean urinary output calculated per hour was found to be 201.03 \pm $62.18 \mathrm{ml} / \mathrm{hr}$. while in group I was $254 \pm 82.98 \mathrm{ml} / \mathrm{hr}$. and group II demonstrated lower urine output (172 $\pm 34.55 \mathrm{ml} / \mathrm{hr}$.). The Mean specific gravity of Group I was observed 1.013 as compared to 1.023 seen in group II. The mean urinary $\mathrm{pH}$ was $6.56 \pm 1.35$, but group I shows $6.9 \pm 0.96$ and $6.2 \pm 0.59$ in group II subjects.

Intergroup comparison was done between the two groups by applying the t-test. The difference of urine output was found to be statistically significant between group I and group II $(P=0.001)$, suggesting subjects with higher BMI had the lowest mean urinary output as compared to group I comprises of normal BMI. Though intergroup analysis of mean specific gravity and mean $\mathrm{pH}$ demonstrated higher $\mathrm{pH}$ of urine and specific gravity in group II as compared to group I, but difference was not found to be statistically significant. Correlation coefficient was calculated to determine relationship between Urinary output/hr., specific gravity and $\mathrm{pH}$. It was observed urinary output showed positive correlation $(r=0.403)$ between urine output $/$ $\mathrm{hr}$ and BMI. The relationship between Specific gravity or $\mathrm{pH}$ and BMI demonstrated bizarre pattern.

\section{Discussion}

Increased risk of renal disease has been demonstrated in the healthy subjects having increased BMI (more than $25 \mathrm{~kg} / \mathrm{m}^{2}$ ) possibly due to altered renal hemodynamics [6]. Krikken, et al described relationships between body mass index (BMI), salt intake, glomerular filtration rate, and filtration fraction in healthy young men [7]. The purpose of our study was to investigate the impact of increased BMI on fluid \& electrolyte balance inn healthy subjects after oral load of $500 \mathrm{ml}$ water. It is seen that healthy subjects with BMI of more than $30 \mathrm{~kg} / \mathrm{m}^{2}$ had decreased urine output $/ \mathrm{hr}$ as compared to those with BMl between $20-2930 \mathrm{~kg} / \mathrm{m}^{2}$. The findings of the present study reveal a positive inverse relationship between BMI and hourly urine output [Fig-1], thus suggests the possibility of variations in normal renal hemodynamic process. The possible underlying mechanism of the decreased urine output could be (i) induced thermogenesis by oral fluid load (ii) fluid retention attributed to dietary salt through processed food intake, leading the cascade of physiological process, finally results in to increased water related fat store, weight gain or elevated leptin hormone level which may increase renal sympathetic out-flow and cause increase sodium retention and volume expansion [8]. Recently it has been hypothesized that adipocytokines secretion from adipose tissue together with cytokines may be the key players of the feedback loop between adipose tis- sue and feeding centers of the central nervous system, responsible abnormal feeding regulation leading to weight gain and associated changes in cardiovascular -renal physiology [9].

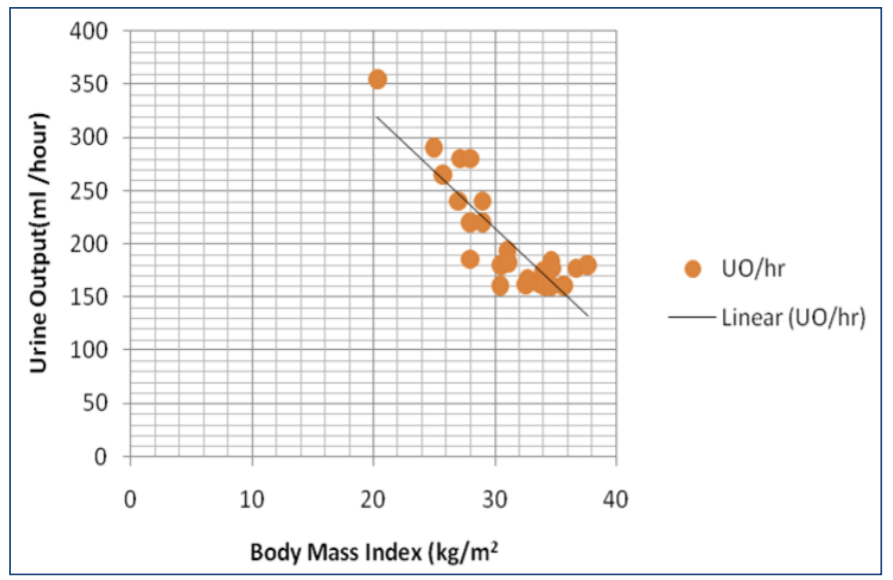

Fig. 1- Correlation between variation in BMl and Urine output per hour

Present study measured the specific gravity and $\mathrm{pH}$ of urine to estimate hydration status and solute concentration. It was observed that subjects with higher BMI $\left(30-38 \mathrm{~kg} / \mathrm{m}^{2}\right)$ demonstrated increase in the specific gravity and decrease in urine $\mathrm{pH}$ as compared to subjects with BMI ranging $20-29 \mathrm{~kg} / \mathrm{m}^{2}$.

The relationship between urine $\mathrm{pH}$ and $\mathrm{BMI}$ in patients of renal stones, urolithiasis has been investigation in several studies[10-12] and found positive correlation. It has been reported that with increase in $\mathrm{BMI}$, the $\mathrm{pH}$ of the urine declines. Increased prevalence of history of renal stone is directly associated with increase in BMI [13]. The possible reason of decrease in $\mathrm{pH}$ with increase in $\mathrm{BMI}$ is reported to be the hyperinsulinaemia or insulin resistances which may cause alter renal salt and water handling mechanism [14].

\section{Conclusion}

The finding of the present study suggest that possibly it may be the altered fluid electrolyte balance in normal healthy adults, which is responsible for increased water -related weight gain leading to increase in fat storage and result in increased body mass index (BMI). Future research is warranted to understand the mechanism of action of adipocytokines or other key players of the feedback loop between adipose tissue and neuroendocrine centers, responsible abnormal renal hemodynamics and weight gain.

\section{References}

[1] Iseki K., Ikemiya Y., Kinjo K. et al. (2004) Kidney Int., 65, 18701876.

[2] Taylor E.N. and Curhan G.C. (2009) Clin. J. Am. Soc. Nephrol., 4(12), 1980-1987.

[3] Jae Dong Chung, Tae-Hyoung Kim, Soon Chul Myung, Young Tae Moon, Kyung Do Kim, and In Ho Chang (2012) Korean J. Urol., 53(4), 268-274.

[4] Siener R., Glatz S., Nicolay C. and Hesse A. (2004) Obes. Res., 12, 106-113.

[5] Hsu C.Y., McCulloch C.E., Iribarren C. et al. (2006) Ann. Intern. Med., 144, 21-28.

[6] Eknoyan and Garabed (2007) Nephrology Dialysis Transplantation, 23(1), 47-51. 
[7] Krikken J.A., Lely A.T., Bakker S.J.L., Navis G. (2007) Kidney Int., 71, 260-265.

[8] Esler M., Rumantir M., Wiesner G. (2001) Am. J. Hypertens., 14, 304S-309S.

[9] Boschmann M., Steiniger J., Hille U., Tank J., Adams F., Sharma A.M., et al (2003) J. Clin. Endocrin. Metab., 88, 6015-6019.

[10]Dmitrieva N.I., Burg M.B. (2005) Mutat. Res., 569, 65-74.

[11]Keller U., Szinnai G., Bilz S., Berneis K. (2003) Eur. J. Clin. Nutr., 57, S2, S69-S74.

[12]Stookey J.D. (2001) Eur. J. Clin. Nutr., 55, 349-359.

[13]Abrass C.K. (2004) J. Am. Soc. Nephrol., 15, 2768-2772.

[14]Malnick S.D., Knobler H. (2006) Qjm, 99(9), 565-79. 